\title{
Assessment of Site of Airways Obstruction By "Spirometry"
}

\author{
Author
}

\section{Dr S. Meenakshi}

Retired Professor of Physiology, Madras Medical College, Chennai- 3600003

At Present as Prof \& HOD of Physiology Dept, SRM Dental College, Ramapuram, Chennai- 89

\begin{abstract}
Airway obstruction at Extra thoracic (central) or intra thoracic (peripheral) level can be satisfactorily diagnosed by recording conventional spirographic tracings using simple standard instruments such as Peak Flow meter and closed spirometer which are easily available in all Hospitals. Ventilatory parameters and certain Ratios derived from them which would permit maximum separation between normal subjects and those with central or peripheral airway obstruction are to be routinely performed in all laboratories for assessment of the site and degree of airway obstruction and treatment. The merits of these different parameters are discussed over here
\end{abstract}

\section{INTRODUCTION}

Obstructing lesion of trachea and larynx cause predominantly" Inspiratory obstruction". Chronic airway obstruction of "Intra thoracic airways " bring about Expiratory obstruction. The extra/ intra thoracic airways obstruction can be determined by flow-volume loops using sophisticated equipment and the results depend upon the cooperation and effort of the patient ${ }^{(1)}$. But the flow-volume loops are not easy to construct and the interpretation is not always clear. ${ }^{(2)}$. It Is possible that extra/intra thoracic airways obstruction can be satisfactorily diagnosed using simple standard instruments such as Peak Flow Meter and Expirograph which are routinely available in all hospitals. The ventilatory parameters and certain ratios obtained from conventional forced expiratory spirogram
(FEVC) and forced inspiratory spirogram (FIVC) --which is the reverse of forced expiratory spirogram which permits normal separation between normal subjects and those with central (extra thoracic) or peripheral (intra thoracic) airway obstruction become the most sensitive indices for diagnosis are established in this study.

\section{MATERIALS AND METHODS}

A total number of 19 subjects participated in the study. Patients were divided into 2 groups. Group 1 consisted of 9 members, identified with upper airway obstruction (ie central or extra thoracic airway obstruction). (Table1).

Group 11 consisted of 10 subjects with confirmed diagnosis of intra thoracic (ie with peripheral) airway obstruction (Table2). 
Conventional forced expiratory spirogram was recorded and from the best of the 3 efforts FEVC, FEV1, FEV1\% and FEFR25-75\% were determined. The forced inspiratory spirogram was also recorded for the same subjects. In this the subject was asked to take a deep inspiration after forcible expiration (the procedure is reverse of forced expiratory maneuver). FIVC, FIV1 and
FIV1\% and FIFR25-75\% were calculated from the best of the 3 tracings. Each patient's forced expiratory/ inspiratory capacities were also recorded (FEC1/FIC1) from tidal breathing (for details of the procedure refer ${ }^{(3,4)}$.

Peak Expiratory Flow Rate was determined using Wright's Peak Flow Meter. Ratios between expiratory / inspiratory counterpart were made.

\begin{tabular}{|c|c|c|c|c|c|c|c|c|c|}
\hline \multirow{4}{*}{$\begin{array}{l}\text { No. Sex \& } \\
\text { Age } \\
\\
\text { (1) (2) }\end{array}$} & \multirow{4}{*}{$\begin{array}{c}\text { Etiology and } \\
\text { Diagnosis } \\
\text { (3) }\end{array}$} & \multirow{3}{*}{\multicolumn{2}{|c|}{ 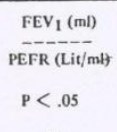 }} & \multirow{2}{*}{\multicolumn{2}{|c|}{$\begin{array}{l}\mathrm{FEV}_{1}(\mathrm{ml}) \\
\mathrm{FIV}_{1}(\mathrm{ml})\end{array}$}} & \multirow{2}{*}{$\begin{array}{l}\mathrm{FEV}_{1} \% \\
\mathrm{FIV}_{1} \%\end{array}$} & \multirow{3}{*}{$\begin{array}{c}\text { PEFR Lit/mt } \\
\text { FEFR Lit/mt } \\
25-75 \% \\
\mathrm{P}<.01\end{array}$} & \multirow{3}{*}{ 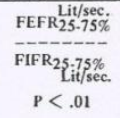 } & $\mathrm{FEC}_{1}(\mathrm{ml})$ \\
\hline & & & & & & & & & $\mathrm{FIC}_{1}(\mathrm{ml})$ \\
\hline & & & & $P<.05$ & & $P<.3$ & & & $\mathrm{P}<.01$ \\
\hline & & (4) & & (5) & & (6) & (7) & (8) & (9) \\
\hline \multirow[t]{2}{*}{ 1. F 52} & Vocal Cord Palsy & 799 & & 799 & & 79.7 & 90 & & 828 \\
\hline & (Unilat). & & 8.9 & 627 & 1.27 & $7^{-4.16}$ & 75 & $\overline{0.45}^{2.8}$ & $\begin{array}{ll}-\overline{650} & 1.27\end{array}$ \\
\hline \multirow[t]{2}{*}{ 2. F 37} & Tracheal Obst. & 1693 & & 1693 & & $84 \quad$ & 280 & 1.82 & 1130 \\
\hline & (Goitre) & $\overline{280}$ & 6.05 & $\overline{722}^{2}$ & 2.35 & $\overline{41}^{-2.05}$ & 87 & $\overline{0.63}^{2.9}$ & $\overline{535} \quad 2.11$ \\
\hline \multirow[t]{2}{*}{ 3. $\mathrm{M} 53$} & Dysphagin, & 2414 & & 2414 & & 89.5 & 300 & 4.39 & 1165 \\
\hline & $\begin{array}{l}\text { Hoarseness Voice } \\
\text { (Hypothyroid) }\end{array}$ & $\overline{300}$ & 8.05 & $\overrightarrow{1411}$ & 1.71 & $54-1.66$ & $-z^{263} 1.14$ & $\overline{1.61}^{2.73}$ & $\begin{array}{ll}\overline{990} & 1.18\end{array}$ \\
\hline \multirow{2}{*}{ 4. M 35} & Post Tracheal & 1254 & & 1254 & & 54 & 160 & 1.35 & 1420 \\
\hline & Stenosis & $\overline{160}$ & 7.84 & $\overline{831}$ & 1.51 & $\overline{41}^{-1.32}$ & $\overline{71}^{1.98}$ & $\overline{1.27}^{1.06}$ & $\begin{array}{ll}\overline{800} & 1.78\end{array}$ \\
\hline \multirow{2}{*}{ 5. M 42} & Press. Trachea \& & 533 & & 533 & & 47 & & 0.32 & 954 \\
\hline & $\begin{array}{l}\text { Maj. Bronchus } \\
\text { (Medias. Tumor) }\end{array}$ & $\overline{60}$ & 8.88 & $\overline{408}$ & 4.31 & $\begin{array}{ll}-- & 1.27 \\
37 & \end{array}$ & $\begin{array}{l}-\overline{-}^{3} \\
19.2\end{array}$ & $\overline{0.27}^{1.18}$ & $\overline{668}{ }^{1.43}$ \\
\hline \multirow{2}{*}{ 6. M 41} & Laryngeal stenosis & 2445 & & 2445 & & 82 & 195 & & 1133 \\
\hline & (Intubation 15 days) & $\overline{195}$ & 12.5 & $\overline{1912}$ & 1.28 & $\overline{73}^{-1.12}$ & -1621.2 & $--^{1.88}$ & $\overline{775} \quad 1.46$ \\
\hline \multirow[t]{2}{*}{ 7. M 37} & Tracheal stenosis & 1756 & & 1756 & & 86 & 220 & 3.34 & 900 \\
\hline & (assist. ventila) & & 7.98 & $\overline{1035}$ & 1.7 & $\overline{56}^{1.53}$ & 200 & 2.07 & $\overline{355}^{2.54}$ \\
\hline \multirow[t]{2}{*}{ 8. M 38} & Carcinoma Left & 2195 & & 2195 & & 70 & 185 & & 1675 \\
\hline & Vocal Cord & & 11.9 & $\overline{1756}$ & 1.25 & $-\overline{6 r}^{-1.06}$ & -1.23 & $\overline{1.76}^{1.42}$ & $\overline{1001}^{1.67}$ \\
\hline \multirow[t]{2}{*}{ 9. M 45} & Laryngeal Tumour & 1500 & & & & & & & \\
\hline & & $\overline{340}$ & 4.4 & $\overline{1053}$ & 1.43 & 41.1 .32 & $\overline{112}^{3.01}$ & $\overline{0.99}{ }^{1.90}$ & $\overline{1120}^{1.60}$ \\
\hline
\end{tabular}




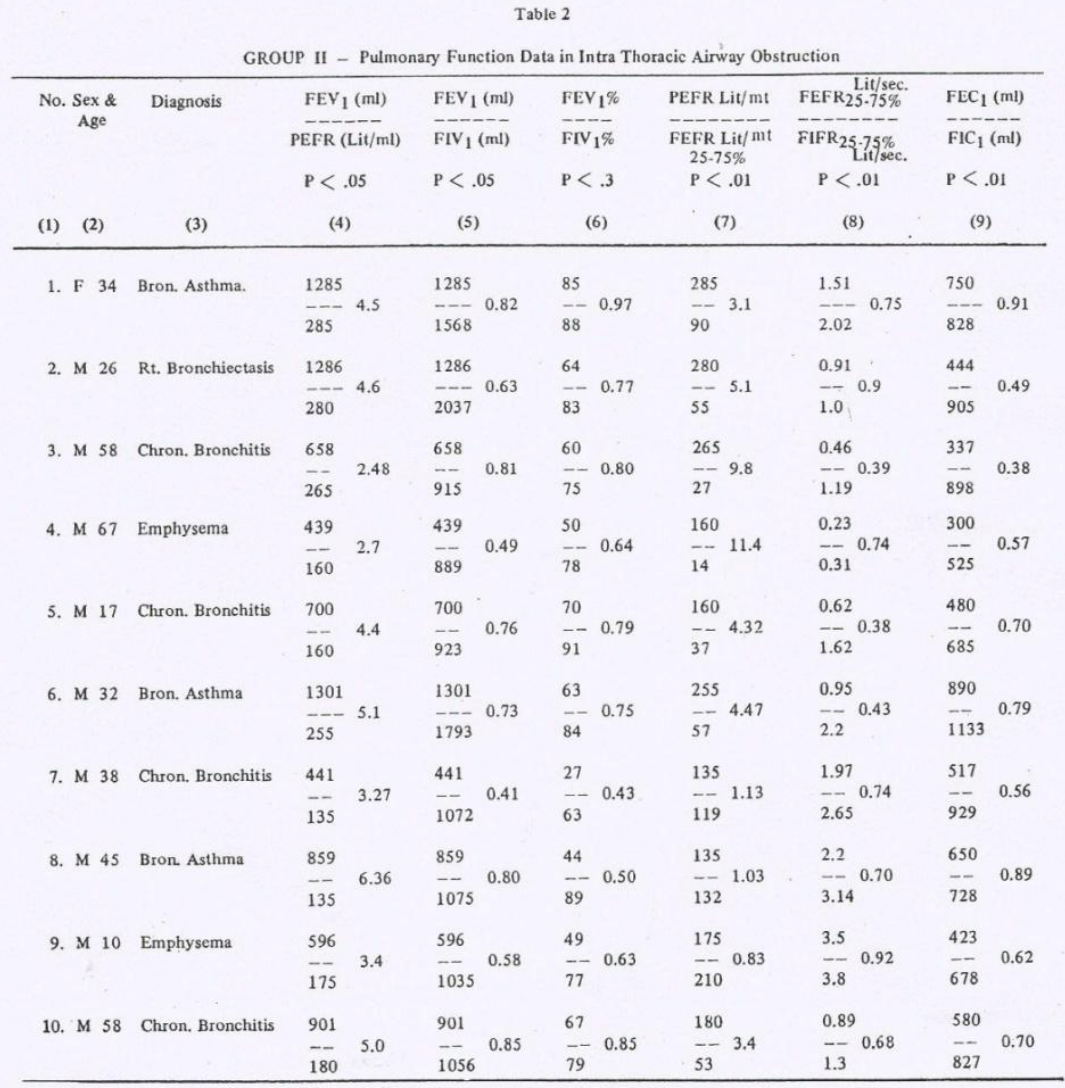

\section{RESULTS and OBSERVATION}

In Group1 with extra thoracic airway obstruction the inspiratory volume(FIVC, FIV1) and forced inspiratory flow rate (FIFR25-75\%) were significantly reduced than the forced expiratory volumes (FEVC, FEV1) and flow rate (FEFR25$75 \%$ ) whereas in Group11 as the patients have intra luminal airway obstruction and so FEVC, FEV1 and FEFR25-75\% were more reduced.
Therefore in Group1 the ratios between Forced Epiratory/ Inspiratory volumes and flow- rates such as FEV1/FIV1 and FEFR25-75\%/FIFR25$75 \%$ were more than" 1 " and In Group11 the ratios were less than 1 (normal 0.9)

PEFR/FEFR25-75\% is less than normal in Group 1 whereas it is raised in G roup11 (Normal 3.74) Similarly FEC1/FIC1 ratio is also increased in Group1 and reduced in Group11 (Normal 0.86) 


\section{DISCUSSION}

FEV1/FIV1 index is not seriously affected by variability of effort and therefore it is a satisfactory measurement to be made for our study.

Clark T.J.H. ${ }^{(5)}$ has identified that obstructing lesions of trachea and larynx cause Predominantly inspiratory airway obstruction which can be satisfactorily diagnosed by measuring FIVC, FIV1 and FIV1\%.

Similarly chronic airway obstruction involving intra thoracic airways can be measured by recording FEVC, FEV1, \& FEV1\%. ${ }^{(6)}$

FEV1 \& its \% are much more reduced in expiratory obstruction and FIV1 \& its percentage $(\%)$ is reduced in inspiratory obstruction. So also the flow rates. Expiratory/Inspiratory Flow-rates are reduced at all levels in corresponding airway obstruction.

Based on previous studies it is well established that the ratios of corresponding parameters from FEVC/FIVC are much useful for detection of ventilatoy defect.

The ratio between Expiratory/ Inspiratory flowvolume exceeds " 1 " in central airways obstruction and the ratios between Expiratory/ Inspiratory volumes and flow rates become less than " 1 " in peripheral airways obstruction.

As more than one parameter is necessary for better indications in lung function studies, ratios derived by many authors have been studied and compared. PEFR denotes abnormalities of large, central airways and FEFR25-75\% signify peripheral airways disease and the ratio between PEFR/FEFR25-75\% has been suggested by Bhella et ${ }^{(9)}$ as a more effective index in separating upper airway obstruction from peripheral airway obstruction.

FEV1/ PEFR found to be a satisfactorily indirect method for assessing upper airway obstruction was suggested by Empey DW ${ }^{(10)}$. The ratio of PEFR/MMFR 50 recommended by YERNAULT.J.C ${ }^{(11)}$ shows a fall in upper airway obstruction and reversal in Bronchial Asthma and COPD.
Miller and Hyatt (12) claim the ratio of MEF50/MIF50 9 (ie midexpiratory flow at 50 /mid inspiratory flow at 50) aid in the deduction and characterization of major airway obstruction and it is effort independent. It is more than 1 in upper airway obstruction.

The ratio between FEFR25-75\%/FIFR25-75\% shown in the present study is SIMILAR to mid expiratory and mid inspiratory flow(FEF50/FIF50) for discrimination of extra/intra thoracic airway obstruction.

Changshin (13) concludes that inspiratory flow should be measured in any patient with unexplained dyspnoea or hyperapnoea even if expiratory (regular) spirogram is normal. Increase in MMEF/MMIF ratio is diagnostic of upper airway obstruction and decrease in this ratio is for diagnosing peripheral airway obstrucyion.

A comparative study of different parameters and ratios suggested by above authors are made in the present study to see which parameter would permit maximum separation between normal and those with central /peripheral airways obstruction and which are the most sensitive index of early upper airway obstruction.

It is found in the present study that FEFR25$75 \% / F I F R 25-75 \%$ is a more sensitive parameter in separating upper airway obstruction and peripheral airway obstruction. $(\mathrm{P}<0.1)$.

In laboratories where only provision for recording Forced Expiratory Spirogram, and peak flow meter are available, PEFR/FEFR25-75\% may be used as a parameter to identify extra/intra thoracic airway obstruction. (P less than $<0.1$ )

The ratio between FEC1/FIC shown in this study is equally effective in signifying upper airway obstruction and intra luminal airway obstruction. ( $\mathrm{P}$ less than <0.1) The method of determination of FEC1 and FIC1 does not lead to any discomfort in older subjects as well as patients who are much dispnoeic. ${ }^{(4)}$

To conclude we would suggest to have at least 2 ratios of expiratory and inspiratory counterpart for the site and degree of assessment of Extra/Intra thoracic airway obstruction. 
REFERENCES

1. Jordanoglou.J, Pride. N.B. A Comparison Of Maximal Inspiratory Flow And Maximal Expiratory Flowin Health And Lung Diseases. Thorax.23.38-45 1968

2. Jordonoglou.J. And Pride. N.B. Factors Determining Maximum Inspiratory Flow And Maximum Expiratory Flow Of Lung.Thorax.33-57.1968

3. Meenakshi.S.Spirogram Recording At Low And High Lung Volumes13 Lung11. 237-239. 1984.

4. An Easy Method Of Spirometry For Ill And Aged Subjects International Journal Of Scientific Research And Publications. (Ijsrp-) Volume3/ Issue1/ Jan 2013.

5. Clark.T.J.H.Inspiratory Obstruction. Brit. Med.J.30.682-6841970.

6. Henshaw.H.C.Murrey.J.F.Diseases Of The Chest. $4^{\text {th }}$ Edi.606-6271980

7. miller.D.R.And Hyatt.R.E.Obstructing Lesions Of Larynx And Trachea And Physiological Characteristics. Mayo. Clin. Proc.44.145-165.1969..

8. Engstrom H.Grumbyg. Dynamic Spirometry In Patients With Tracheal Stenosis. Acta. Med. Scand.176.329-335.1964

9. Bhalla.J.S Pande.J.N.Physiological Charcteristics Of Upper Airway Obstruction. Ind.Med.J \&Med/Res.69.476-481-1979

10. Empey. D. W . Assessment Of Upper Airway Obstruction. Brit. Med. J. 1.26 503-505. 1972

11. Yernault .J.C .Englert.M. Upper Airway Stenosis. A Phtsiologic Study. - 108.9961000.1973 Amer.

12. Miller.D.R. Hyatt.R.E.Evaluation Of Obstructing Lesions Of The Trachea And Larynxby Flow-Volume Loops. Amer. Rev.Res.Dis. Rev.Respir. Dis.108.475-485 1973

13. Changhin. Henry.William.N Jr. Amer. Rev.Respir.Dis.106.233-2381972.
Pulmonary Function Data In Extra Thoracic Airway Obstruction 